\title{
Update: Rationale and design of the Sodium Lowering In Dialysate (SoLID) trial: a randomised controlled trial of low versus standard dialysate sodium concentration during hemodialysis for regression of left ventricular mass
}

\author{
Joanna Leigh Dunlop ${ }^{1,2}$, Alain Charles Vandal ${ }^{3,4}$, Janak Rashme de Zoysa ${ }^{5}$, Ruvin Sampath Gabriel, Imad Adbi Haloob , \\ Christopher John Hood ${ }^{2}$, Philip James Matheson ${ }^{8}$, David Owen Ross McGregor ${ }^{9}$, Kannaiyan Samuel Rabindranath ${ }^{10}$, \\ David John Semple ${ }^{11}$ and Mark Roger Marshall ${ }^{1,2,12^{*}}$
}

\begin{abstract}
After the publication of our paper Dunlop et al. "Rationale and design of the Sodium Lowering In Dialysate (SoLID) trial: a randomised controlled trial of low versus standard dialysate sodium concentration during hemodialysis for regression of left ventricular mass", we became aware of further data correlating left ventricular (LV) mass index at baseline and their correpsonding mass at 12 months, using cardiac margnetic resonanace imaging (MRI) in patients on hemodialysis. The original published sample size for the SoLID trial of 118 was a conservative estimate, calculated using analysis of covariance and a within person Pearson's correlation for LV mass index of 0.75 . New data communicated to the SoLID trial group has resulted in re-calcuation of the sample size, based upon a within person Pearson's correlation of 0.8 but otherwise unchanged assumptions. As a result, the SoLID trial will now recruit 96 participants.
\end{abstract}

\section{Update}

After the publication of our paper Dunlop et al. "Rationale and design of the Sodium Lowering In Dialysate (SoLID) trial: a randomised controlled trial of low versus standard dialysate sodium concentration during hemodialysis for regression of left ventricular mass" [1], we became aware of further data correlating left ventricular (LV) mass index at baseline and their correpsonding mass at 12 months, using cardiac margnetic resonanace imaging (MRI) in patients on hemodialysis.

The original published sample size for the SoLID trial of 118 was a conservative estimate, calculated using repeatedmeasures analysis of covariance (ANCOVA) and a within person Pearson's correlation for LV mass index of 0.75 .

\footnotetext{
* Correspondence: mrmarsh@woosh.co.nz

${ }^{1}$ Auckland Clinical School, Faculty of Medical and Health Sciences, University of Auckland, Private Bag 93311, Otahuhu, Auckland 1640, New Zealand ${ }^{2}$ Department of Renal Medicine, Middlemore Hospital, Counties Manukau District Health Board, Private Bag 93311, Otahuhu, Auckland 1640, New Zealand

Full list of author information is available at the end of the article
}

The assumption of a correlation of 0.75 was based on private communication from the Jardine group (private communication P Mark 8/2/2011) [2-4]: in a cohort of 59 patients of their patients with repeated measures of LVMI at least 6 months apart (using cardiac MRI), correlation was 0.87 ( $\mathrm{p}<0.001)$ with normally distributed data. Modelling these data, and allowing for $25 \%$ for drop outs, it was determined that 59 participants would be enrolled in each arm (power 0.8, alpha 0.05).

New data communicated to the SoLID trial group has resulted in us re-calculating sample size for the SoLID trial (private communication C McIntyre and A Odudu 30/4/2014) [5]: in a cohort of 44 patients of their patients with repeated measures of LV mass index 12 months apart (using cardiac MRI), correlation was $0.81(\mathrm{p}<0.001)$. In 21 of these patients, there was an intervention that might have modestly affected their LV mass index; however, restricting analysis to the 23 paired values in the control group provides a similar correlation of 0.83 . 
Based on the data above, the sample size has been recalculated using a within person correlation of 0.8 , but otherwise unchanged assumptions. It is was determined that 48 participants will be enrolled in each arm. The change in sample size has been approved by the National (New Zealand) Multi-region Ethics Committee (IRB00004663) of the New Zealand Ministry of Health (IORG0000895), and the primary funding body for this study the Health Research Council of New Zealand.

\section{Competing interests}

The authors declare that they have no competing interests.

\section{Authors' contributions}

JLD participated in the trial design, and drafted the manuscript. ACV participated in the trial design, developed the statistical plan, and helped to draft the manuscript. MRM conceived and developed the trial, and participated in the statistical plan and helped to draft the manuscript. RSG, $\mathrm{IAH}$, and DORM participated in design and development of the trial, and helped to draft the manuscript. JRdZ and PJM participated in the trial design and coordination, and helped to draft the manuscript. CJH, KSR, and DJS participated in the trial coordination and implementation, and helped to draft the manuscript. All authors read and approved the final manuscript.

\section{Acknowledgments}

The SoLID trial is funded through grants from the Health Research Council of New Zealand, the Maurice and Phyllis Paykel Trust and the Royal Australasian College of Physicians (RACP) Research Foundation. JLD is a current recipient of an RACP Jacquot Research Entry Scholarship, and MRM is a current recipient of an RACP Jacquot Research Establishment Fellowships. The SoLID trial research team would like to acknowledge the kindness of the Jacquot Family in supporting nephrological research in Australasia, and the kindness of Mr and Mrs Kwun Kwok and their son Mr Siu Hang Kok for supporting nephrological research at Counties Manukau District Health Board. The SoLID trial research team would also like to acknowledge the Australasian Kidney Trial Network (http://www.aktn.org.au), for providing advice and assistance on the design of the trial.

\footnotetext{
Author details

${ }^{1}$ Auckland Clinical School, Faculty of Medical and Health Sciences, University of Auckland, Private Bag 93311, Otahuhu, Auckland 1640, New Zealand. ${ }^{2}$ Department of Renal Medicine, Middlemore Hospital, Counties Manukau District Health Board, Private Bag 93311, Otahuhu, Auckland 1640, New Zealand. ${ }^{3}$ Faculty of Health and Environmental Sciences, Auckland University of Technology, North Shore Campus, Private Bag 92006, Auckland 1142, New Zealand. ${ }^{4}$ Ko Awatea, Middlemore Hospital, Counties Manukau District Health Board, Private Bag 93311, Otahuhu, Auckland 1640, New Zealand. ${ }^{5}$ Renal Service, North Shore Hospital, Waitemata District Health Board, Private Bag 93503, Takapuna, Auckland 0740, New Zealand. 'Department of Cardiology, Middlemore Hospital, Counties Manukau District Health Board, Private Bag 93311, Otahuhu, Auckland 1640, New Zealand. ${ }^{7}$ Bathurst Health Service, New South Wales, Australia. ${ }^{8}$ Department of Nephrology, Wellington Hospital, Capital \& Coast District Health Board, Private Bag 7902, Wellington South, New Zealand. ${ }^{9}$ Department of Nephrology, Christchurch Hospital, Canterbury District Health Board, Private Bag 4710, Christchurch, New Zealand. ${ }^{10}$ Department of Renal Medicine, Waikato Hospital, Waikato District Health Board, Private Bag 3200, Hamilton 3240, New Zealand. ${ }^{11}$ Department of Renal Medicine, Auckland City Hospital, Auckland District Health Board, Private Bag 92024, Auckland, Auckland 0740, New Zealand. ${ }^{12}$ Medical Affairs Renal (Asia Pacific), Baxter Healthcare, P.O. Box 14062, Panmure, Auckland 1741, New Zealand.
}

Received: 11 February 2015 Accepted: 11 February 2015

Published online: 01 August 2015

\section{References}

1. Dunlop JL, Vandal AC, de Zoysa JR, Gabriel RS, Haloob IA, Hood CJ, et al. Rationale and design of the Sodium Lowering In Dialysate (SoLID) trial: a randomised controlled trial of low versus standard dialysate sodium concentration during hemodialysis for regression of left ventricular mass. BMC Nephrol. 2013;14:149.

2. Mark PB, Patel RK, Jardine AG. Are we overestimating left ventricular abnormalities in end-stage renal disease? Nephrol Dial Transplant. 2007;22(7):1815-9.

3. Patel RK, Jardine AG, Mark PB, Cunningham AF, Steedman T, Powell JR, et al. Association of left atrial volume with mortality among ESRD patients with left ventricular hypertrophy referred for kidney transplantation. Am J Kidney Dis. 2010;55(6):1088-96.

4. Patel RK, Oliver S, Mark PB, Powell JR, McQuarrie EP, Traynor JP, et al. Determinants of left ventricular mass and hypertrophy in hemodialysis patients assessed by cardiac magnetic resonance imaging. Clin J Am Soc Nephrol. 2009;4(9):1477-83.

5. Odudu A, Eldehni MT, Fakis A, Mclntyre CW. Rationale and design of a multi-centre randomised controlled trial of individualised cooled dialysate to prevent left ventricular systolic dysfunction in haemodialysis patients. BMC Nephrol. 2012;13:45.

\section{Submit your next manuscript to BioMed Central and take full advantage of:}

- Convenient online submission

- Thorough peer review

- No space constraints or color figure charges

- Immediate publication on acceptance

- Inclusion in PubMed, CAS, Scopus and Google Scholar

- Research which is freely available for redistribution 